\title{
Comparison of Free Radical Scavenging Activity of Siamese Neem Tree (Azadirachta indica A. Juss var. siamensis Valeton) Leaf Extracts Prepared by Different Methods of Extraction
}

\author{
Pongtip Sithisarn $^{\mathrm{a}}$ Roongtawan Supabphol ${ }^{\mathrm{b}}$ Wandee Gritsanapan $^{\mathrm{a}}$ \\ ${ }^{a}$ Department of Pharmacognosy, Faculty of Pharmacy, Mahidol University, and ${ }^{b}$ Department of Physiology, \\ Faculty of Medicine, Srinakarinwirote University, Bangkok, Thailand
}

\section{Key Words}

Siamese neem tree - Antioxidant activity .

2,2-diphenyl-1-picrylhydrazyl-scavenging assay against the DPPH radical. The most active extract was obtained with the leaf decoction method. It showed antioxidant activity with $\mathrm{EC}_{50}$ of $31.4 \mu \mathrm{g} / \mathrm{ml}$.

Copyright (C) 2006 S. Karger AG, Basel

\section{Introduction}

The molecular bases of many diseases such as inflammation, cardiovascular diseases and cancer are known to involve oxidative stress caused by free radicals. Recently, considerable research has been directed at natural antioxidants, in particular their protective effect against biological damages due to free radicals [1].

Azadirachta indica A. Juss var. siamensis Valeton or Siamese neem tree is a large evergreen tree which belongs to the Meliaceae family. This plant is abundantly found in every part of Thailand and has been used as traditional medicine for many purposes [2]. The flowers are used as element tonic, and for treatments of fever and nasal polyposis. The stem bark is used for the treatment of diarrhea and ameobic dysentery. The leaves are also used as element tonic, to stimulate gastric secretion, for treatment of fever and as insecticide. Furthermore, in Thailand, the young leaves and young flowers of Siamese neem tree are commonly consumed as a cooked vegetable [3]. Siamese neem tree has been screened for antioxidant

\section{KARGER}

Fax +41613061234

E-Mailkarger@karger.ch

www.karger.com
(C) 2006 S. Karger AG, Basel

1011-7571/06/0153-0219\$23.50/0

Accessible online at:

www.karger.com/mpp
Wandee Gritsanapan

Department of Pharmacognosy

Faculty of Pharmacy, Mahidol University

447 Sri-Ayuthaya Rd., Ratchatewi, Bangkok 10400 (Thailand)

Tel. +66 2644 8677, ext. 1500, 5530, Fax +66 2644 8701, E-Mail pywgs@mahidol.ac.th 
property, and it was found that it could promote high antioxidant activity [4]. This plant shows free radical scavenging activity against the 2,2-diphenyl-1-picrylhydrazyl $(\mathrm{DPPH})$ and ABTS radicals and can also inhibit lipid peroxidation of Chago K-1 cell line induced by UV irradiation [5]. These reports suggest that Siamese neem tree can probably be used as a health food.

Thus, the objective of this research was to investigate the antioxidant activity of the aqueous extracts of leaves of Siamese neem tree from several extracting and drying methods including percolation, decoction, maceration, soxhlet extraction, spray drying and freeze drying.

\section{Materials and Methods}

\section{Plant Material}

The leaves of Azadirachta indica A. Juss var. siamensis Valeton were collected from Ratchaburi province, Thailand, during the period from December 2001 to March 2002. The plant samples were compared with the herbariums (SN207325) at Bangkok Herbarium, Botanical Section, Botany and Weed Science Division, Department of Agriculture, Bangkok. The voucher specimens were deposited at the same place (BK 63512).

\section{Chemicals}

Quercetin, rutin and DPPH - were obtained from Sigma-Aldrich Chemical company (St. Louis, Mo., USA).

Preparation of Siamese Neem Tree Leaf Extracts from

Different Extracting and Drying Methods

Decoction

Fresh leaves were boiled with distilled water (1:10) for $6 \mathrm{~h}$ and then filtered. The filtrate was evaporated on a hot water bath to yield dried leaf decoction extract.

\section{Maceration}

Fresh leaves were dried in a hot air oven $\left(55^{\circ} \mathrm{C}\right)$ for $6 \mathrm{~h}$ and then moderately powdered. The powdered drug was separately macerated with $20,50,80$ and $95 \%$ ethanol $(1: 20, \mathrm{w} / \mathrm{v})$ at $25^{\circ} \mathrm{C}$ for 7 days and then filtered. The filtrates were evaporated on a hot water bath to yield dried leaf 20, 50, 80 and 95\% ethanolic maceration extracts.

\section{Percolation}

Fresh leaves were dried in a hot air oven $\left(55^{\circ} \mathrm{C}\right)$ for $6 \mathrm{~h}$ and then moderately powdered. The powdered drug was separately percolated with 50,80 and $95 \%$ ethanol $(1: 20, \mathrm{w} / \mathrm{v})$ for $24 \mathrm{~h}$. The percolates were evaporated on a hot water bath to yield dried leaf 50, 80 and $95 \%$ ethanolic percolation extracts.

\section{Soxhlet Extraction}

Fresh leaves were dried in a hot air oven $\left(55^{\circ} \mathrm{C}\right)$ for $6 \mathrm{~h}$ and then moderately powdered. The powdered drug was separately extracted using soxhlet apparatus with 80 and $95 \%$ ethanol $\left(60-80^{\circ} \mathrm{C} ; 1: 50\right.$, $\mathrm{w} / \mathrm{v})$ for $6 \mathrm{~h}$ and then filtered. Ethanol was removed using a rotary evaporator to yield dried leaf 80 and $95 \%$ ethanolic soxhlet extracts.
Freeze Drying

For the preparation of water extraction, the fresh leaves were minced into small pieces and mixed with 10 volumes of distilled water using a magnetic stirrer for $6 \mathrm{~h}$. Then the extract was filtered over a Whatman filter paper. The filtrate was frozen and lyophilized in a lyophilizer under pressure to yield freeze-dried leaf extract.

\section{Spray Drying}

Fresh leaves were boiled with distilled water (1:10,w/v) for $6 \mathrm{~h}$ and then filtered. The filtrate was spray dried to yield spray dried leaf extract.

\section{Determination of Antioxidant Activity by the DPPH}

\section{Scavenging Method}

Antioxidant activity of extracts of Siamese neem tree leaves from the above extraction methods and of standard solutions (quercetin and rutin) were determined based on the radical scavenging ability in reacting with a stable DPPH free radical [6]. A total of $750 \mu \mathrm{l}$ of the extract (concentrations $50-1,000 \mu \mathrm{g} / \mathrm{ml}$ ) or standard were added to $750 \mu \mathrm{l}$ of DPPH in absolute ethanol solution $(152 \mu M)$ using an eppendorf tube $(1.5 \mathrm{ml})$. After incubation at $37^{\circ} \mathrm{C}$ for $20 \mathrm{~min}$, the absorbance of each solution was determined at $520 \mathrm{~nm}$ using Shimadzu U160 ultraviolet spectrophotometer (4973C SPEC, Shimadzu, Kyoto, Japan). The corresponding blank readings were also taken and percent inhibition was then calculated as follows:

$$
\% \text { Inhibition }=\frac{\left(\mathrm{A}_{\text {blank }}-\mathrm{A}_{\text {extract }}\right) \times 100}{\mathrm{~A}_{\text {blank }}}
$$

The $\mathrm{EC}_{50}$ value, the concentration of sample required for $50 \%$ scavenging of the DPPH free radical, was determined from the curve of percent scavenging plotted against the concentration. Each sample was tested in triplicate. The average of the $\mathrm{EC}_{50}$ value was then calculated.

\section{Thin-Layer Chromatographic Fingerprints}

Based on the antioxidant activity obtained from the extraction methods, decoction extract was selected for thin-layer chromatography (TLC). The TLC was performed on TLC precoated silica gel $60 \mathrm{GF}_{254}$ plate $10 \times 10 \mathrm{~cm}$ (Merck, Germany) using chloroform: ethyl acetate:methanol:formic acid $(7: 2: 1: 1)$ as mobile phase. TLC plate was detected using CAMAG viewing box UV detector (022.9055, CAMAG, Muttenz, Switzerland), and natural productpolyethylene glycol spraying reagent under UV $366 \mathrm{~nm}$ was used for flavonoid detection (fig. 1).

\section{Results}

The yield of the crude extracts and free radical scavenging activity of the extracts are given in table 1 . The freeze drying method gave the highest yield of crude extract $(51.50 \%, \mathrm{w} / \mathrm{w})$, while the decoction method gave the most active extract for DPPH-scavenging activity $\left(\mathrm{EC}_{50}\right.$ : $31.41 \mu \mathrm{g} / \mathrm{ml}$ ). Maceration, percolation and soxhlet extraction with various concentrations of ethanol (20-95\%) gave high yield of crude extracts $(10-25 \%$, w/w), but the 

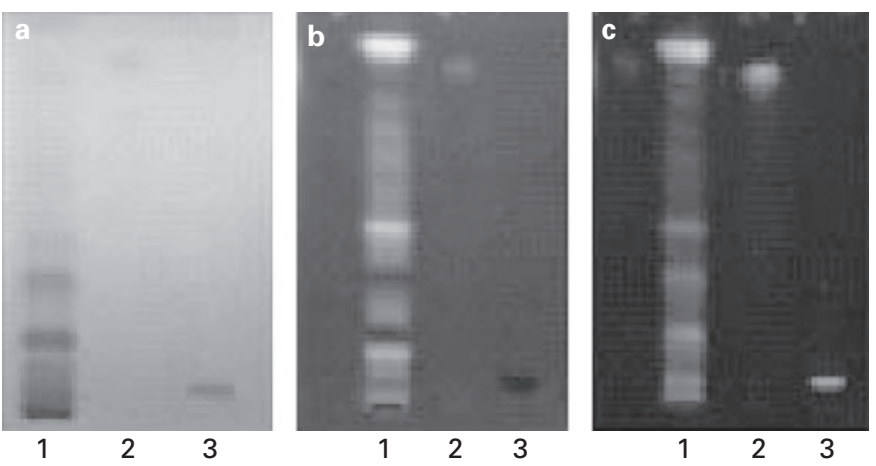

Fig. 1. Thin-layer chromatogram of Siamese neem tree leaf extract obtained using decoction. a UV $254 \mathrm{~nm}$. b UV $366 \mathrm{~nm}$. c NP/PEG spraying reagent + UV $366 \mathrm{~nm} .1=$ Siamese neem tree leaf decoction extract; 2 = standard quercetin; 3 = standard rutin. Adsorbent: silica gel GF60. Solvent system: chloroform/ethyl/acetate/methanol/formic acid $(7: 2: 1: 1)$.

extracts showed lower antioxidant activity $\left(\mathrm{EC}_{50}: 122-\right.$ $265 \mu \mathrm{g} / \mathrm{ml})$. The spray-dried extract also gave high antioxidant activity $\left(\mathrm{EC}_{50}: 36.28 \mu \mathrm{g} / \mathrm{ml}\right)$, but the yield of the crude extract was low $(3.04 \%$, w/w). Although the freezedried extract gave a high yield of crude extract $(51.50 \%$, $\mathrm{w} / \mathrm{w})$, it gave medium antioxidant activity $\left(\mathrm{EC}_{50}\right.$ : $74.19 \mu \mathrm{g} / \mathrm{ml}$ ). The thin-layer chromatogram of the decoction extract showed the spots equivalent to quercetin and rutin flavonoids, whose antioxidant activities to the $\mathrm{DPPH}$ radical were $\mathrm{EC}_{50}$ of 2.29 and $34.67 \mu \mathrm{g} / \mathrm{ml}$, respectively.

\section{Discussion}

The freeze drying method gave the highest yield but medium antioxidant activity, while the decoction and spray drying methods gave a low yield but high antioxidant activity (table 1), indicating that the active antioxidant components in the leaves were better extracted by hot water than ethanol. Compared with the other methods, decoction method was simple, convenient and carried low cost in terms of reagents and instrumentation. As it is economical, the decoction extraction method can be used in other countries, especially in developing countries. However, many modern extraction methods have been studied and developed for preparation of plant extracts; these include ultrasonic extraction [7], microwaveassisted extraction [8] and pressurized liquid extract [9]. These methods have different advantages that include improvement of the penetration of solvent into plant par-
Table 1. Yield of crude extracts and free radical scavenging activity of Siamese neem tree leaves prepared using different extracting and drying methods

\begin{tabular}{lcr}
\hline Extracts & $\begin{array}{l}\text { \% yield } \\
(\mathrm{w} / \mathrm{w})\end{array}$ & \multicolumn{1}{c}{$\begin{array}{c}\mathrm{EC}_{50} \\
\mu \mathrm{g} / \mathrm{ml}\end{array}$} \\
\hline Decoction extract & 8.15 & 31.41 \\
20\% ethanol maceration extract & 20.39 & 265.05 \\
50\% ethanol maceration extract & 20.38 & 201.45 \\
80\% ethanol maceration extract & 17.50 & 217.08 \\
95\% ethanol maceration extract & 10.88 & 265.18 \\
50\% ethanol percolation extract & 24.58 & 122.01 \\
80\% ethanol percolation extract & 21.48 & 236.86 \\
95\% ethanol percolation extract & 13.80 & 169.88 \\
80\% ethanol soxhlet extract & 20.14 & 140.30 \\
95\% ethanol soxhlet extract & 17.62 & 148.57 \\
Freeze-dried extract & 51.50 & 74.19 \\
Spray-dried extract & 3.04 & 36.28 \\
Quercetin & - & 2.29 \\
Rutin & - & 34.67 \\
\hline
\end{tabular}

Quercetin and rutin were used as standard antioxidant compounds.

ticles and using low extraction temperature that effects the stability of active components for ultrasonic extraction [7]. The microwave-assisted method promotes better yield and fast-speed extraction process of specific active components such as glycyrrhizic acid in liquorice [8]. With pressurized liquid extraction the thermal labile and polar bioactive compounds such as berberine, baicalin and glycyrrhizin could be extracted [9]. Thus these methods for plant extraction could reduce extraction time and promote the efficiency of high-quality extraction of specific active components, but at a higher cost than the decoction method. Yet, these modern methods should be considered for extracting higher quality and quantity of Siamese neem tree leaves for pharmaceutical production.

Thin-layer chromatogram of the decoction extract showed the spots of quercetin and rutin flavonoids which should play an important role in free radical scavenging activity of the extract. This suggested that boiling the leaves with water or decoction should be the appropriate method for extraction of the leaves of Siamese neem tree to promote a high yield of these antioxidant flavonoids that could inhibit lipid peroxidation in Chago K-1 cell line as previously reported [5]. 


\section{Conclusion}

The freeze drying method gave the highest yield of the crude extract of Siamese neem tree leaves. The extracts had antioxidant activity against the DPPH radical. Thinlayer chromatogram of the decoction extract showed spots of quercetin and rutin flavonoids. The quantitative analysis of antioxidant components will be further investigated.

\section{Acknowledgement}

This project was supported by the Royal Golden Jubilee $\mathrm{PhD}$ Program and the Thailand Research Fund No. 5.PN.MU/46/A.1.

\section{References}

1 Cross EC: Oxygen radicals and human diseases. Ann Intern Med 1987; 107:526-545.

2 Sombatsiri K, Ermel K, Schmutterer H: Other meliaceous plants containing ingredients for integrated pest management and further purpose; in Schmutter H (ed): The Neem Tree Azadirachta indica A. Juss. and Other Meliaceous Plants. VCH Verlagsgesellschaft, Weinheim, 1995, p 589.

3 Clayton T, Soralump P, Chaukul W, Temsiririrkkul R: Medicinal Plants in Thailand. Amarin Printing, Bangkok, 1996, vol 1, p 44.
4 Suttajit S, Khansuwan U, Suttajit M: Antioxidative activity of Thai medicinal herbs. Thai J Pharm Sci 2002;26:32.

5 Sithisarn P, Supabphol R, Gritsanapan W: Antioxidant activity of Siamese neem tree. J Ethno Pharmacol 2005;99:109-112.

-6 Yamasaki K, Hashimoto A, Kokusenya Y, Miyamoto T, Sato T: Electrochemical method for estimating the antioxidative effects of methanol extracts of crude drugs. Chem Pharm Bull 1994;42:1663-1665.

7 Soares Melecchi MI, Peres VF, Dariva C, Zini CA, Abad FC, Martinez MM, Caramao EB: Optimization of the sonication extraction method of Hibiscus tiliaceus L. flowers. Ultrason Sonochem 2006;13:242-250.
$>8$ Wang Q, Ma S, Fu B, Lee FSC, Wang X: Development of multi-stage countercurrent extraction technology for the extraction of glycyrrhizic acid (GA) from licorice (Glycyrrhiza uralensis Fisch). Biochem Eng J 2004;21:285292.

9 Ong ES, Len SM: Pressurized hot water extraction of berberine, baicalein and glycyrrhizin in medicinal plants. Anal Chim Acta 2003;482: 81-89. 